\title{
Soft Computing Techniques Applications and their Comparisons with Traditional pq Theory Based Control Schemes for Filter in Aircraft System
} Saifullah Khalid ${ }^{*}$

Department of Electrical Engineering, IET Lucknow, India

\begin{abstract}
Constant Instantaneous Power Control Technique for extracting reference currents for shunt APF (active power filters) have been modified using Artificial Neural Network and Fuzzy logic control and their performances have been compared. The acute analysis of different comparisons of the compensation capability supported total harmonic distortion and speed is going to be done, and suggestions are going to be given for the selection of technique to be used. The simulated results using MATLAB model are shown, and that they can without doubt prove the importance of the projected control technique of aircraft shunt APF.
\end{abstract}

Keywords: Aircraft electrical system; Shunt active power filter; Constant instantaneous power control strategy; ANN; THD

\section{Introduction}

Non-linear loads cause the unbalancing, harmonics, distortion etc into the power arrangement and these unwanted problems turn out profusely of problems within the system. Whenever application of such loads can increase, source gets distorted and unbalanced. These currents foul the supply purpose of the utility. Therefore, it's necessary to compensate unbalance, a harmonic and reactive element of the load currents. Whereas once source is unbalanced and distorted, these problems worsen the system [1-3].

Today, the soft computing techniques like Fuzzy algorithms, ATS algorithms, Genetic Algorithm [4-12], particle swarm optimization [13], ANN [14-18] applied in every machinery and filter devices for optimization of the system applied or in the various control system.

In this paper, ANN based mostly and fuzzy logic (FLC) controller are wont to mend the whole performance of active filter for reduction of harmonics and other related drawbacks generated into the balanced, unbalanced and distorted system because of the nonlinear loads [1]. The simulation results clearly show their effectiveness. The simulation results non-heritable with the new model are abundant improved than those of traditional methodology.

The paper has been described during a successive manner. The APF define and also the load underneath contemplation is mentioned in Section II. The control algorithmic rule for APF converses in Section III. MATLAB/Simulink based mostly simulation results are conferred in Section IV, and eventually Section V concludes the paper.

\section{System Depiction}

The aircraft power system is a three-phase power system with the source frequency of 400 Hertz. As depicted in Figure 1, Shunt Active Power Filter gets better the power quality and balances the harmonic currents in the source supply system [19-23]. The APF is realized by using VSI connected at the PCC to a common Direct Current (DC) link voltage [24-27].

One three-phase rectifier in parallel with an inductive load and an unbalanced load connected in a phase with the midpoint, one three phase rectifier connects a pure resistance directly, and one three phase rectifier connects a pure resistance directly. These loads have been considered as load 1,2 and 3 respectively. All three loads are connected to both of the supply at such interval or together such that ability of APF can be evaluated and it has been tested for 15 cycles. The circuit parameters are given in Appendix.

\section{Control Theory}

The proposed control of APF depends on constant instantaneous power control (CIPC) strategy, and it has been optimized for artificial Neural Network and Fuzzy Logic Control.Constant instantaneousPower Control strategy has been discussed in brief in this section. The following section also deals with the primary application of ANN and FLC in the control schemes [24,28,29].

\section{Constant Instantaneous Power Control Strategy (C.I.P.C.)}

The control illustration of APF using CIPC approach is exposed in Figure 2. Four low pass filters have been out in the open in the control block. Three are with cut off frequency of 6.4 Kilo Hertz. They are useful to filter the voltages. Even as the other one is used for the power $\mathrm{p}_{0}$. The phase voltages cannot be unswervingly used in the control block. The

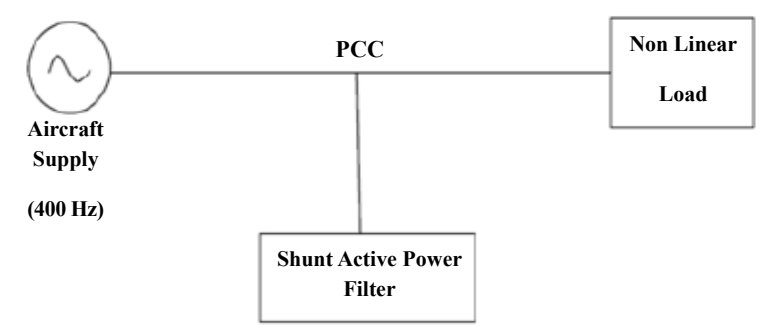

Figure 1: Aircraft system (400 Hertz) using Shunt Power Filter.

*Corresponding author: Saifullah Khalid, Department of Electrical Engineering, IET Lucknow, India, Tel: +91-522-2361692; Fax: +91-522-236163; E-mail: saifullahkhalid@Outlook.com

Received September 09, 2016; Accepted October 14, 2016; Published October 21, 2016

Citation: Khalid S (2016) Soft Computing Techniques Applications and their Comparisons with Traditional pq Theory Based Control Schemes for Filter in Aircraft System. J Electr Electron Syst 5: 201. doi:10.4172/2332-0796.1000201

Copyright: @ 2016 Khalid S. This is an open-access article distributed under the terms of the Creative Commons Attribution License, which permits unrestricted use, distribution, and reproduction in any medium, provided the original author and source are credited. 
grounds are the instability matter. The voltage harmonics beyond the 6.4 kilo hertz in the array of resonance frequency are blocked using the low pass filters.

$\mathrm{P}, \mathrm{q}, \mathrm{p}_{0}, \mathrm{v}_{\alpha}$ and $\mathrm{v}_{\beta}$ are completed following the computation from $\alpha-\beta-0$ conversion and send to the $\alpha-\beta$ current reference block. $\alpha-\beta$ Current reference block computes I' $I_{c \alpha}$ and i'c $c_{\beta}$. To finish, $\alpha-\beta-0$ inverse conversion block computes the current references. Thereafter, it is applied to the Pulse Width Modulation (PWM) current control.

\section{Application of ANN based control}

In this paper, CIPC approach has been represented by an ANN fabricated of two hidden layers among 10 neurons every one and one output layer with three neurons. The logarithmic commencement function is the support of the two hidden layers neurons, and linear commencement function intended for the output layer neurons.

As shown in Figure 3, the ANN has seven inputs $\left(v_{a}, v_{b}, v_{c}, d c\right.$ voltage error, $\left.i_{a}, i_{b}, i_{c}\right)$ and three outputs $\left(i_{r a}, i_{r b}, i_{r}\right)$ as observed in the different strategies. The reference current generation unit and $\mathrm{dc}$ voltage controller unit has been modeled and their individual and simultaneous effect has been observed.

\section{Application of fuzzy logic control}

The fuzzy logic control has been employed in the dc voltage control round of the APF. In fuzzy, the plan employs centrifugal defuzzification

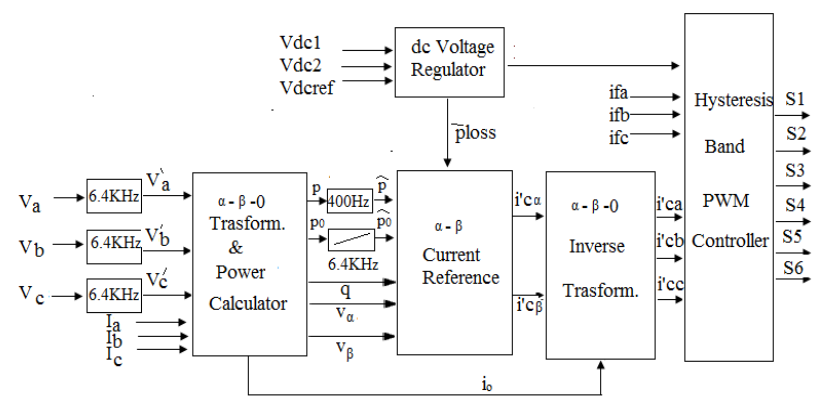

Figure 2: Control block diagram of the shunt active filter using constant instantaneous power control strategy.

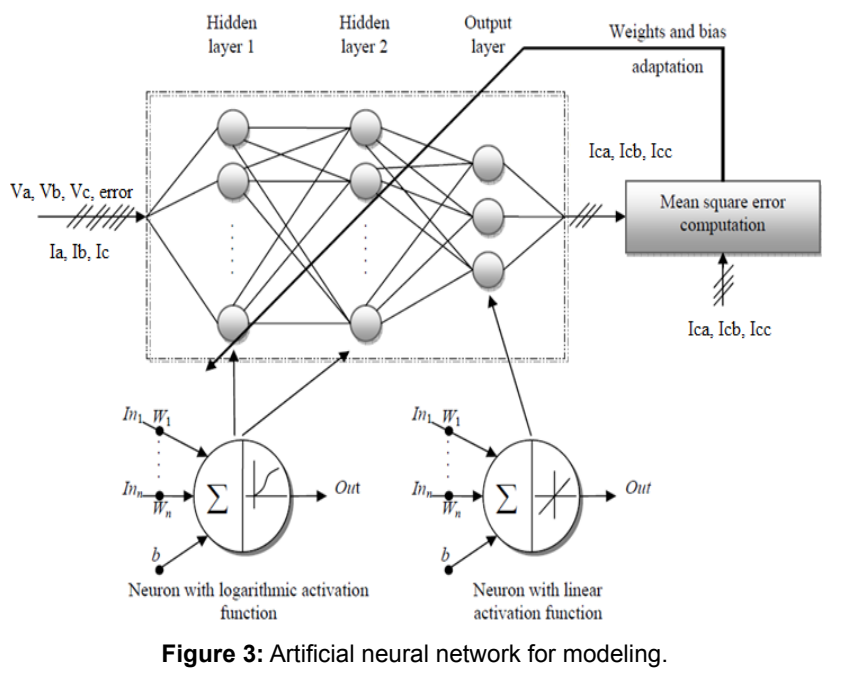

manner. There are 2 inputs; error and its derivative and 1 output, that is the command signal. The two inputs uses Gaussian membership functions while the output uses triangle membership function. Table 1 explains the fuzzy control rule and Figure 4 illustrates the membership functions used.

\section{Simulation Results and Discussions}

The proposed scheme of APF is simulated in MATLAB environment to estimate its performance. Three loads have been applied together at a different time interval to check the affectivity of the control schemes for the reduction of harmonics. A small amount of inductance is also connected to the terminals of the load to get the most effective compensation. The simulation results clearly reveal that the scheme can successfully reduce the significant amount of THD in source current and voltage within limits.

\section{Uncompensated system}

When all three loads are connected as per the configuration discussed in the previous section, Total harmonic distortion (THD) of source (supply) current has been observed as nine point five percent and THD of source (supply) Voltage were one point five five percent. In this duration, the APF is not connected. The results are shown in Figure 5 . By observant this information, we are going to merely understand that they are not within the limit of the international standard.

\section{Compensated System}

The performance of APF under different loads connected, when utilizing ANN Control has been discussed below for the control strategy given below.

\section{For constant instantaneous power control strategy}

From Figure 6 it has been empiric that that the THDs of source current and source voltage were $3.01 \%$ and $1.88 \%$ respectively. The compensation time was $0.0147 \mathrm{sec}$. At $\mathrm{t}=0.0147 \mathrm{sec}$, it is apparent that the waveforms for source voltage and source current have become sinusoidal. Figure 6 shows the waveforms of compensation current, DC capacitor voltage, and load current.

\begin{tabular}{|c|c|c|c|}
\hline Error & Negative & Zero & Positive \\
\hline Negative & Big Negative & Positive & Big Positive \\
\hline Zero & Big Negative & Zero & Big Positive \\
\hline Positive & Big Negative & Negative & Big Positive \\
\hline
\end{tabular}

Table 1: Fuzzy logic rule.

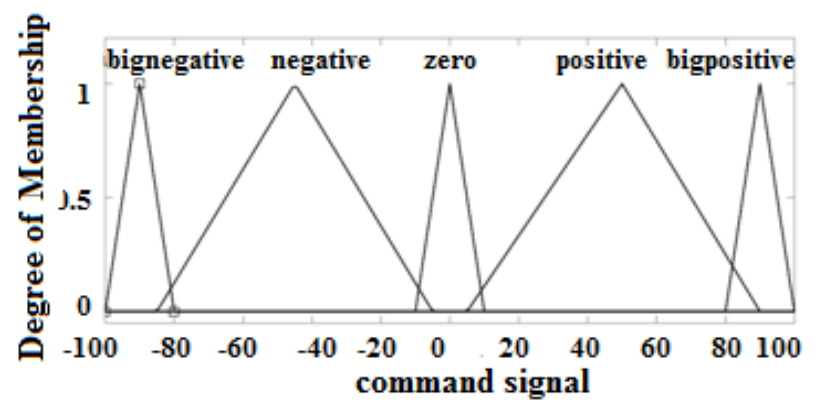

Figure 4: Membership functions. 
Citation: Khalid S (2016) Soft Computing Techniques Applications and their Comparisons with Traditional pq Theory Based Control Schemes for Filter in Aircraft System. J Electr Electron Syst 5: 201. doi:10.4172/2332-0796.1000201

Page 3 of 5

The aberration in dc voltage can be acutely apparent in the waveforms. As per claim for accretion the compensation current for accomplishing the load current demand, it releases the energy, and after that it accuses and tries to achieve its set value. If we carefully observe, we can acquisition out that the compensation current is, in fact, accomplishing the appeal of load current, and afterward the active filtering the source current and voltage is affected to be sinusoidal.

For constant instantaneous power control strategy using ANN

THDs of source current and source voltage have been found $2.84 \%$ and $1.78 \%$ respectively after making observations from the simulation results shown in Figure 7. The waveforms for source voltage and source current have become sinusoidal at $\mathrm{t}=0.0066 \mathrm{sec}$. Compensation time
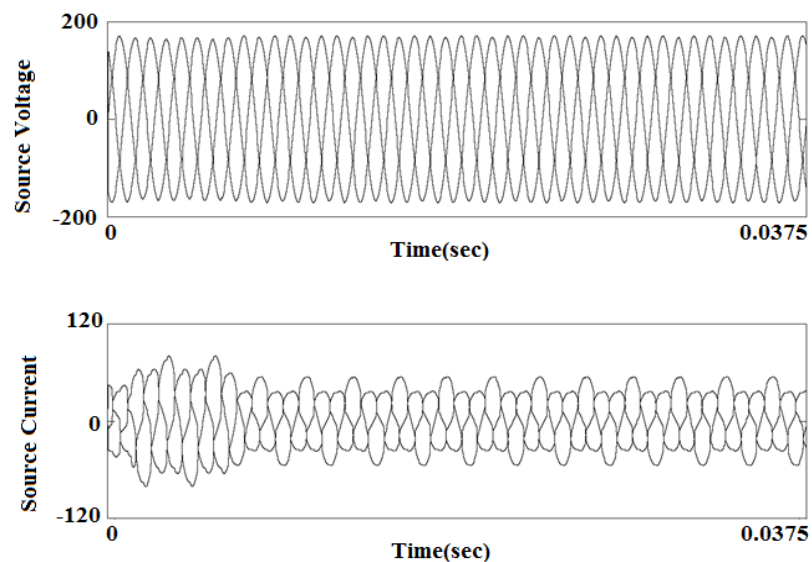

Figure 5: Source Voltage and source current waveforms of uncompensated system.
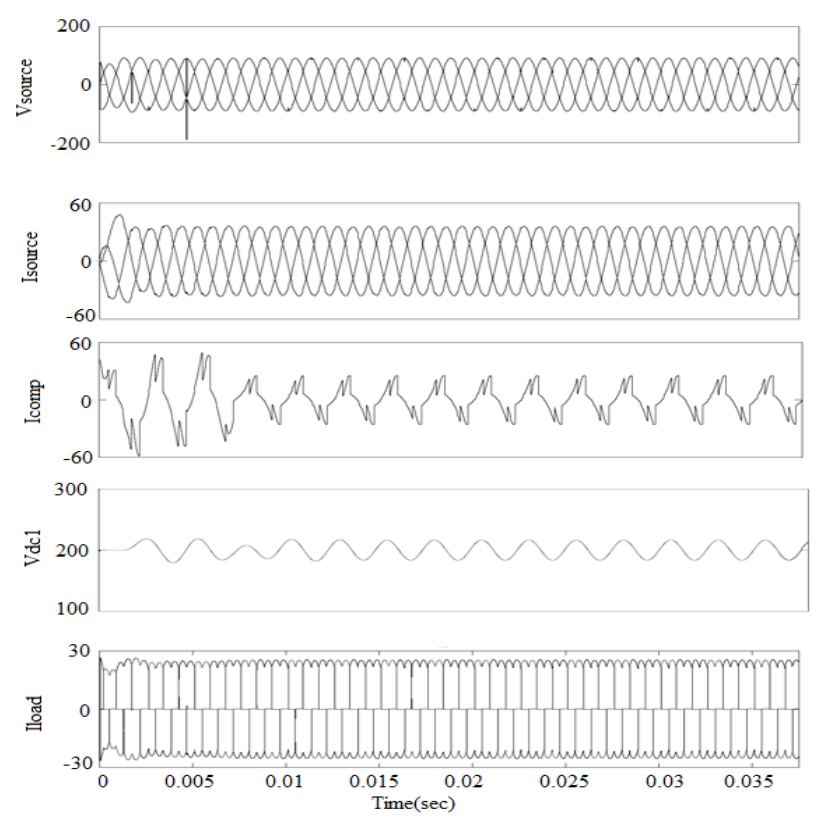

Figure 6: Source Voltage, source current, compensation current (phase b), DC link Voltage and load current waveforms of Active power filter using constant instantaneous power control strategy. is $0.0066 \mathrm{sec}$. The waveforms of compensation current, dc capacitor Voltage, and load current have been shown in Figures 6 and 7 . Waveforms show the variations in dc capacitor voltage. Whenever the demand for high load current comes, it releases the energy that in turn increases the compensation current. Later on, it charges and tries to regain its previous set value. By making a simple observation, we can say that compensation current is fulfilling the demand of load current. After the active filtering, the source current and voltage is forced to be sinusoidal.

\section{For constant instantaneous power control strategy using} fuzzy logic control

THDs of source current and source voltage have been found 2.33\% and $1.03 \%$ respectively after making observations from the simulation results shown in Figure 8. The waveforms for source voltage and source current have become sinusoidal at $\mathrm{t}=0.0044 \mathrm{sec}$. Compensation time is $0.0044 \mathrm{sec}$. The waveforms of compensation current, dc capacitor Voltage, and load current have been shown in Figure 8. Waveforms show the variations in dc capacitor voltage. Whenever the demand for high load current comes, it releases the energy that in turn increases the compensation current. Later on, it charges and tries to regain its previous set value. By making a simple observation, we can say that compensation current is fulfilling the demand of load current. After the active filtering, the source current and voltage is forced to be sinusoidal.
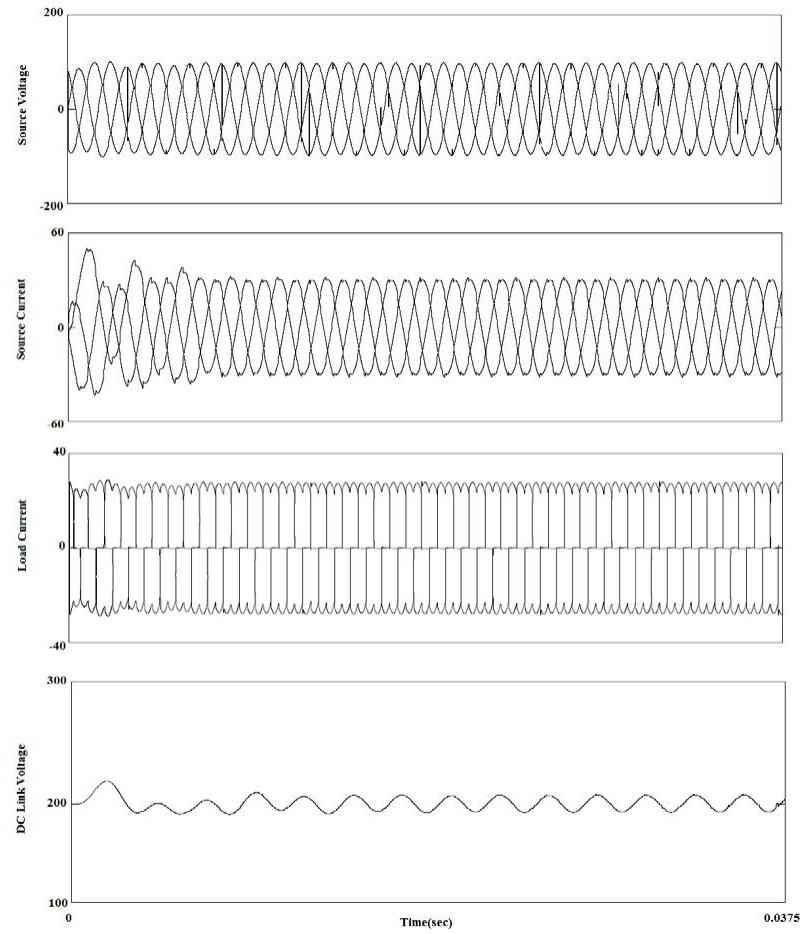

Figure 7: Source Voltage, source current, compensation current (phase b), DC link Voltage and load current waveforms of Active power filter using constant instantaneous power control strategy using ANN.

\begin{tabular}{|c|c|c|c|}
\hline Strategy & THD-I (\%) & THD-V (\%) & Compensation Time (sec) \\
\hline CIPC & 3.01 & 1.88 & 0.0147 \\
\hline CIPC-ANN & 2.84 & 1.78 & 0.0066 \\
\hline CIPC-FLC & 2.33 & 1.03 & 0.0044 \\
\hline
\end{tabular}

Table 2: Summary of simulation results 
Citation: Khalid S (2016) Soft Computing Techniques Applications and their Comparisons with Traditional pq Theory Based Control Schemes for Filter in Aircraft System. J Electr Electron Syst 5: 201. doi:10.4172/2332-0796.1000201
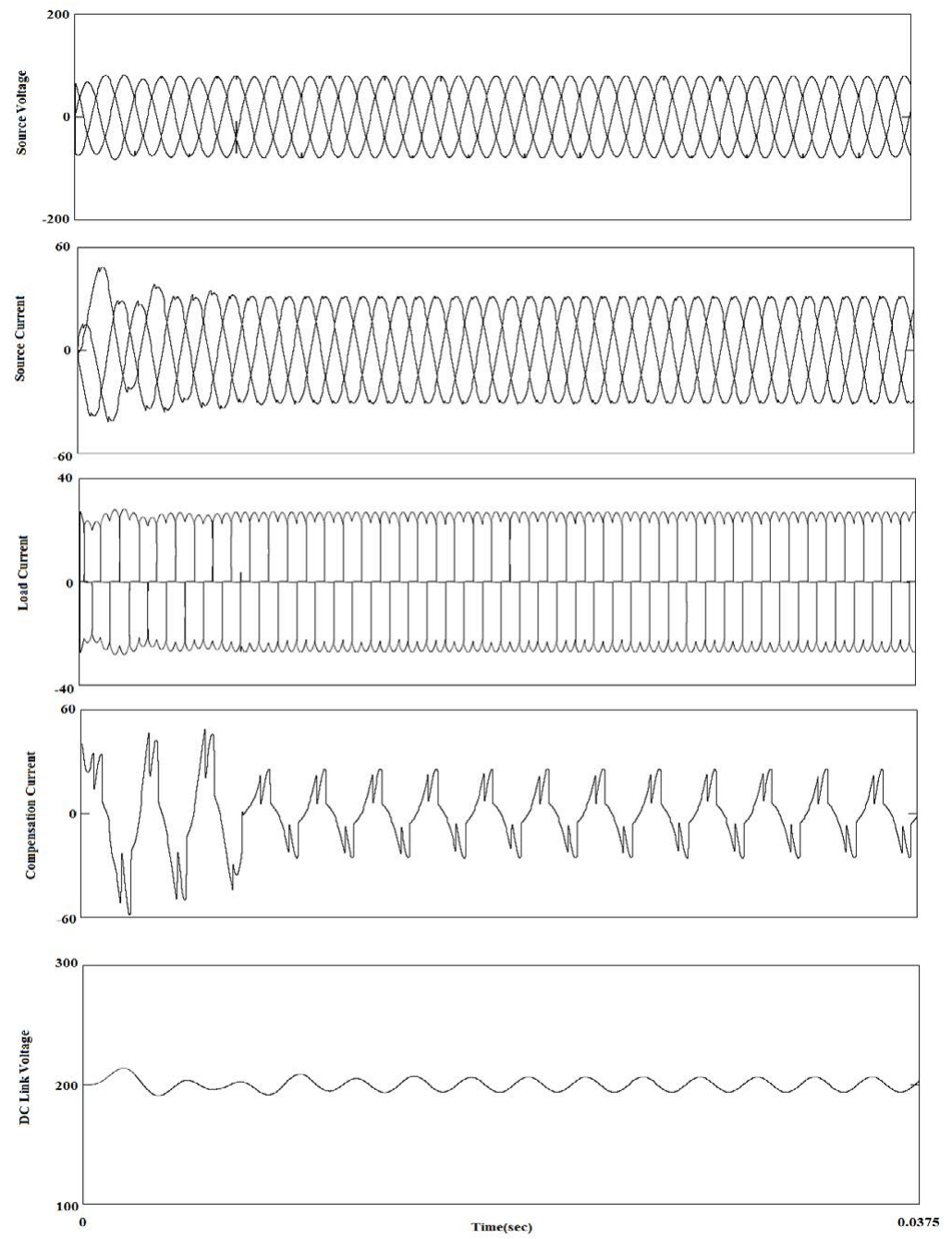

Figure 8: Source Voltage, Source Current, Load Current, Compensation Current (Phase b) and DC Link Voltage Waveforms of Active Power Filter using Constant Instantaneous Power Control Strategy using Fuzzy Logic Control with All Three Loads Connected for Aircraft System.

\section{Comparative analysis of the simulation results}

From the Table 2, we can easily say that Constant Instantaneous Power Control Strategy using Fuzzy Logic Controller (CIPC-FLC) has been found best for current and voltage harmonic reduction. When these results have been compared based on compensation time, it has been also found that CIPC-FLC strategy is also fastest one.

\section{Conclusion}

This paper has done an acute analysis of traditional, ANN and Fuzzy Logic control for shunt APF in aircraft power utility of 400 HZ. Optimum selection of control strategy based on compensation time and THD has been suggested. Overall Constant Instantaneous Power Control Strategy using FLC (CIPC-FLC) has been observed as an optimum choice. Constant Instantaneous Power Control Strategy's performance has been improved, which itself an achievement for the case of optimization in traditional strategies.

\section{Parameters}

The aircraft system parameters are [1]:

Three-phase source voltage: $115 \mathrm{~V} / 400 \mathrm{~Hz}$.
Filter capacitor: $5 \mu \mathrm{F}$,

Filter inductor $=0.25 \mathrm{mH}$.

Dc capacitor: $4700 \mu \mathrm{F}$.

Dc voltage reference: $400 \mathrm{~V}$.

\section{References}

1. Donghua C, Guo T, Xie S, Zhou B (2005) Shunt Active Power Filters Applied in the Aircraft Power Utility. 36th Power Electronics Specialists Conference, PESC 5: 59-63.

2. Saifullah K, Bharti D (2014) Comparative Evaluation of Various Control Strategies for Shunt Active Power Filters in Aircraft Power Utility of $400 \mathrm{~Hz}$. Majlesi Journal of Mechatronic Systems 3: 1-5.

3. Saifullah K, Bharti D (2013) Application of Al techniques in implementing Shunt APF in Aircraft Supply System. Proceeding of SPRINGER- SOCROPROS Conference, IIT-Roorkee 1: 333-341.

4. Guillermin P (1996) Fuzzy logic Applied to Motor Control. IEEE Transactions on Industrial Application 32: 51-56.

5. Hew Wooi AHAP, Hamzah A, Mowed HAF (2002) Fuzzy Logic Control of a three phase Induction Motor using Field Oriented Control Method. Society of Instrument and Control Engineers, SICE Annual Conference 264-267.

6. Jain SK, Agrawal P, Gupta H (2002) Fuzzy logic controlled shunt active power 
Citation: Khalid S (2016) Soft Computing Techniques Applications and their Comparisons with Traditional pq Theory Based Control Schemes for Filter in Aircraft System. J Electr Electron Syst 5: 201. doi:10.4172/2332-0796.1000201

Page 5 of 5

filter for power quality improvement. IEE Proceedings of the Electric Power Applications 149: 317-328.

7. Norman M, Samsul B, Mohd N, Jasronita J, Omar SB (2004) A Fuzzy logic Controller for an Indirect vector Controlled Three Phase Induction Motor Proceedings Analog And Digital Techniques In Electrical Engineering, TENCON 2004, Chiang Mai, Thailand 4: 1-4.

8. Afonso JL, Fonseca J, Martins JS, Couto CA (1997) Fuzzy Logic Techniques Applied to the Control of a Three-Phase Induction Motor. Proceedings of the UK Mechatronics Forum International Conference, Portugal. pp. 142-146.

9. Chiewchitboon P, Tipsuwanpom P, Soonthomphisaj N, Piyarat W (2003) Speed Control of Three-phase Induction Motor Online Tuning by Genetic Algorithm. Fifth International Conference on Power Electronics and Drive Systems, PEDS 1: 184-188.

10. Kumar P, Mahajan A (2009) Soft Computing Techniques for the Control of an Active Power Filter. IEEE Transactions on Power Delivery 24: 452-461.

11. Ismail KB, Abdeldjebar H, Abdelkrim B, Mazari B, Rahli M (2008) Optimal Fuzzy Self-Tuning of PI Controller Using Genetic Algorithm for Induction Motor Speed Control. Int. J. of Automation Technology 2: 85-95.

12. Guicheng W, Min Z, Xu X, Changhong J (2006) Optimization of Controller Parameters based on the Improved Genetic Algorithms. IEEE Proceedings of the 6th World Congress on Intelligent Control and Automation, Dalian, China.

13. Radha T, Chelliah TR, Pant M, Ajit A, Grosan C (2010) Optimal gain tuning of $\mathrm{PI}$ speed controller in induction motor drives using particle swarm optimization. Logic Journal of IGPL Advance Access.

14. Joao OP, Bimal BK, Eduardo BSL (2001) A Stator-Flux-Oriented VectorControlled Induction Motor Drive with Space-Vector PWM and Flux-Vector Synthesis by Neural Networks. IEEE Transaction on Industry Applications 37: 1308-1318.

15. Rajasekaran S, Vijayalakshmi PGA (2005) Neural Networks, Fuzzy Logic and Genetic Algorithm: Synthesis and Applications. Prentice Hall of India, New Delhi, fifth printing.

16. Rojas R (1996) Neural Network- A Systematic Introduction. Spriger-Verlag, Berlin.

17. Zerikat M, Chekroun S (2008) Adaptation Learning Speed Control for a High-
Performance Induction Motor using Neural Networks. Proceedings of World Academy of Science, Engineering and Technology 35: 294-299.

18. Seong-Hwan K, Tae-Sik P, YooJi-Yoon, Gwi-Tae P (2001) Speed-Sensorless Vector Control of an Induction Motor Using Neural Network Speed Estimation. IEEE Transaction on Industrial Electronics 48: 609-614.

19. Saifullah K, Bharti D (2011) Power Quality Issues, Problems, Standards \& their Effects in Industry with Corrective Means. International Journal of Advances in Engineering \& Technology (IJAET) 1: 1-11.

20. Dugan RC, McGranaghan MF, Beaty HW (1996) Electrical Power Systems Quality. New York: McGraw-Hill.

21. Saifullah K, Bharti D (2010) Power Quality: An Important Aspect. Internationa Journal of Engineering, Science and Technology 2: 6485-6490.

22. Ghosh A, Ledwich G (2002) Power Quality Enhancement Using Custom Power Devices. Boston, MA: Kluwer.

23. Khalid S, Vyas N (2009) Application of Power Electronics to Power System University Science Press, INDIA.

24. Aredes M, Hafner J, Heumann K (1997) Three-Phase Four-Wire Shunt Active Filter Control Strategies. IEEE Transactions on Power Electronics 12: 311-318.

25. Saifullah K, Bharti D (2013) Power quality improvement of constant frequency aircraft electric power system using Fuzzy Logic, Genetic Algorithm and Neural network control based control scheme. International Electrical Engineering Journal (IEEJ) 4: 1098-1104

26. IEEE Recommended Practices and Requirements for Harmonic Control in Electrical Power Systems. IEEE Standard 519-1992.

27. Saifullah K, Bharti D, Agrawal N, Kumar N (2007) A Review of State of Art Techniques in Active Power Filters and Reactive Power Compensation. National Journal of Technology 3: 10-18.

28. Saifullah K, Bharti D (2013) Comparison of Control Strategies for Shunt Active Power Filter under balanced, unbalanced and distorted supply conditions. Proceedings of IEEE Sponsored National Conference on Advances in Electrical Power and Energy Systems (AEPES-2013).

29. Saifullah K, Bharti D (2013) Comparative Critical Analysis of SAF using Soft Computing and Conventional Control Techniques for High Frequency $(400 \mathrm{~Hz})$ Aircraft System. Proceeding of IEEE- CATCON Conference. 